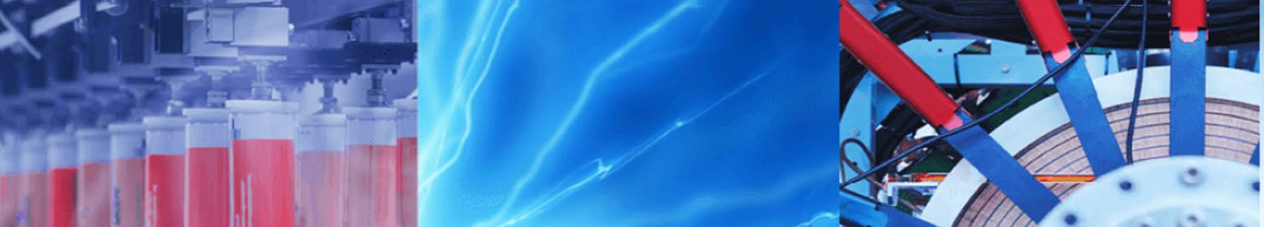

Research Article

\title{
Modification of cementitious composites with graphene oxide and carbon nanotubes
}

\author{
Jianqing Gong ${ }^{1}$ (D) Li Lin $^{1} \cdot$ Sujie Fan ${ }^{1}$
}

Received: 2 May 2020 / Accepted: 27 August 2020 / Published online: 2 September 2020

(c) Springer Nature Switzerland AG 2020

\begin{abstract}
Both graphene oxide (GO) and carbon nanotubes (CNTs) are carbon-based nanomaterials. Due to their favorable dispersibility in water and excellent mechanical properties, they are potential additives for use as reinforcements in cementitious composites. In this laboratory study, GO and CNTs were simultaneously used as additives to improve the mechanical properties (e.g., compressive strength) and durability (e.g., frost resistance, water impermeability) of cementitious composites. To maintain and optimize the mortar fluidity, fly ash ( $20 \%$ by the mass of the cementitious materials) was also added into the cementitious composite. Based on the laboratory test results, the compressive strength of the cementitious composite was maximized to $43.50 \mathrm{MPa}$ with an optimal dosage of $0.08 \% \mathrm{GO}$, by weight of the total mixture. Addition of $0.04 \% \mathrm{GO}$ (by total mixture weight) and higher dosages of up to $0.08 \%$ exhibited a strengthening effect on the cement composites due to the simultaneous bridging effect of $0.15 \%$ CNTs and the nucleation effect of GO. Furthermore, the addition of GO and CNTs contributed to improving the freeze-thawing resistance and impermeability of the cementitious composites. Overall, the study results indicated that the addition of GO and CNTs could potentially improve the mechanical properties and durability of cementitious composites, which could be very beneficial for various industrial applications such as concrete roads or building constructions.
\end{abstract}

Keywords Graphene oxide (GO) · Carbon nanotubes (CNTs) · Cementitious composites · Compressive strength · Freezethawing resistance $\cdot$ Impermeability $\cdot$ Durability

\section{Introduction}

Cement-based concrete is widely used for various civil engineering applications (i.e., buildings, roads, etc.), the properties of which are predominantly determined through strength characterization. Other properties such as impermeability, freeze-thawing resistance, are partially dependent on and affected by the concrete strength. The pore structure is an important factor affecting the strength of the cementitious composites and one key challenge is often how to modify the pore structure and consequently, improve the strength of the cement composite [1,2].
It is reported in the literature that the strength of cementitious composites can be improved by adding high-efficient water-reducers to reduce the water-cement ratio, improve the workability of the cement-matrix composites, and reduce porosity [3]. These water-reducers improved the mechanical properties and durability of cementitious composites to a certain extent by optimizing the composition and structure of materials from different levels. At present, these water-reducers are mainly used to develop the cementitious composites with high compressive strength and good rheology by using the compact packing principle and mixing ratio [4]. For example, adding ultrafine and highly effective active mineral nanometer admixtures such as fly

Jianqing Gong, gongjianqing@hnu.edu.cn | ${ }^{1}$ Key Laboratory for Green and Advanced Civil Engineering Materials and Application Technology of Hunan Province, College of Civil Engineering, Hunan University, Changsha 410082, China. 
ash, granulated blast furnace slag, and natural zeolite powder reduces porosity to improve the durability of cementitious composites [5].

Recently, new nanomaterials with superior physical properties have brought novelty for significantly improving the mechanical properties and durability of cementitious composites for numerous chemical/engineering applications [6, 7]. For example, nano-SiO ${ }_{2}$ material has been successfully used to inhibit the generation and propagation of micro cracks by filling the micro-voids of concrete, which accordingly improved the bearing capacity and fracture toughness of concrete [8, 9]; On the other hand, nano-sized $\mathrm{CaCO}_{3}$ has shown potential to accelerate the hydration reactions of $\mathrm{C}_{3} \mathrm{~A}$ and $\mathrm{C}_{3} \mathrm{~S}$ through seeding effects, which inherently promotes the formation of $\mathrm{C}-\mathrm{S}-\mathrm{H}$ and accordingly enhanced the mechanical properties of concrete [10].

Additionally, as a nanoscale "super fiber" reinforced material, the introduction of carbon nanotubes (CNTs) also improved the micropore filling and toughening performance of concrete [11]. Mohamed et al. found that adding CNTs increased the flexural strength of cement mortar by about $55 \%$ compared to the control group without CNTs [12]. Zhou et al. [13] found that the combination of graphene oxide (GO) and CNTs can improve the strength and toughness properties of cementitious materials.

Similar to mechanical properties, the corrosion resistance and electrical conductivity of cement-matrix composites have also indicated good results through the introduction carbon nanomaterials [14-20]. Several studies in the literature have shown that both GO and CNTs can effectively improve the mechanical properties (e.g., strength) and durability of cementitious composites-however they have adverse effects on the workability aspects [20,21]. Due to its large specific surface area and oxygen-containing functional groups on the surface, $\mathrm{GO}$ can accelerate the formation of hydration products and promote the compact accumulation of hydration products, thus improving the strength, corrosion resistance, and frost resistance of cement-based composites. CNTs, on the other hand, has exhibited great potential to enhance the flexural strength, compressive strength, and flexural toughness of cementitious composites due to their unique atomic structure [22]. However, systemic studies on the influence of different nanomaterial combinations on cementitious materials are limited and mostly in their infancy. For instance, the effects of the GO-CNTs combination on the dispersion of the carbon-based nanomaterials in the cementitious composites has not been widely reported in the literature. Similarly, the literature is fairly limited on studies comparing the effectiveness of using the GO-CNTs combination versus individual additives (i.e. GO alone or CNT alone) on improving the mechanical properties and durability of the cementitious composites. Evidently, these aspects warrant exploration/addressing.

To obtain new cementitious composites with enhanced strength and other improved mechanical properties, multi-walled CNTs and high-purity single-layer GO were used in this study to investigate their effects on workability, compressive strength, frost resistance, and water impermeability of the cementitious composites. Ultimately, it is envisioned that the laboratory data generated, in this study, on the enhanced mechanical properties and durability of cement-matrix composites will lay a solid foundation for the industrial preparation of new cementitious composites in the future. Note that in this paper, the word composite is interchangeably used to mean mixture.

\section{Experimental design plan}

The experimental design is discussed in the subsequent section and includes the materials and laboratory tests. The laboratory tests include workability, mechanical, frost resistance, and impermeability tests.

\subsection{Raw materials}

The cement used in the study was ordinary Portland cement P.O 42.5, with a specific surface area of $314 \mathrm{~m}^{2} \mathrm{~kg}^{-1}$. The main chemical components of cement are shown in Table 1 and the main chemical components of class-F fly ash are shown in Table 2 . The specific surface area and the density of the fly ash were $1400 \mathrm{~m}^{2} \mathrm{~kg}^{-1}$ and $2.22 \mathrm{~g} \mathrm{~cm}^{-3}$, respectively. The size range of the quartz sand employed in the study was $180-380 \mu \mathrm{m}$. The waterreducing agent used was QS-H8011L polycarboxylates, a high-performance water-reducing admixture with low air content (water-reducing rate $>23 \%$ ). Multi-walled CNTs (from Suzhou carbon-rich graphene Technology Co., Ltd.) having an inner diameter of 3-5 $\mathrm{nm}$, an outer diameter of $8-15 \mathrm{~nm}$, length of 3-12 $\mu \mathrm{m}$, specific surface

Table 2 Chemical composition of fly ash

\begin{tabular}{llllll}
\hline Composition & $\mathrm{SiO}_{2}$ & $\mathrm{Al}_{2} \mathrm{O}_{3}$ & $\mathrm{MgO}$ & $\mathrm{CaO}$ & $\mathrm{Fe}_{2} \mathrm{O}_{3}$ \\
\hline Content (\%) & 55.8 & 14.33 & 1.3 & 12.06 & 4.14 \\
\hline
\end{tabular}

Table 1 Chemical composition of cement

\section{SN Applied Sciences}

\begin{tabular}{llllllll}
\hline Composition & $\mathrm{SiO}_{2}$ & $\mathrm{Al}_{2} \mathrm{O}_{3}$ & $\mathrm{MgO}$ & $\mathrm{CaO}$ & $\mathrm{Fe}_{2} \mathrm{O}_{3}$ & $\mathrm{SO}_{3}$ & Loss on ignition \\
\hline Content (\%) & 24.2 & 2.8 & 1.5 & 64.3 & 2.4 & 1.5 & 1.5 \\
\hline
\end{tabular}


area $>233 \mathrm{~m}^{2} \mathrm{~g}^{-1}$, and a purity $>91 \%$ was used. The GO used, was a high-purity, precipitation-free monolayer GO that was laboratory prepared using the Hummer's modified method [23]. The thickness of GO monolayer was $0.6-1.0 \mathrm{~nm}$ with lamella diameter of $0.2-10 \mu \mathrm{m}$ and specific surface area of $1000-1217 \mathrm{~m}^{2} \mathrm{~g}^{-1}$, respectively.

The locally sourced sand, that was used in the study, mostly comprised of fine-graded quartz aggregates. Other materials used in the study, also locally sourced, were ordinary super-plasticizer and water.

\subsection{Preparation of the composite materials}

To ensure uniform dispersion of GO and CNTs in the cementitious mixture, the aqueous solution of $\mathrm{GO}$ was treated with an ultrasonic mixer for $1 \mathrm{~h}$ (at $40 \mathrm{kHz}$ frequency with a $300 \mathrm{~W}$ power input) while the aqueous solution of CNTs used sodium dodecyl benzene sulfonate (SDBS) as the dispersion solution, and was ultrasonically treated for $2 \mathrm{~h}$ (at $33 \mathrm{kHz}$ frequency with a $200 \mathrm{~W}$ power input) before mixing with the mortar. The water-cement ratio used was 0.3 [24]. The respective mixture proportions are shown in Table 3.

Based on the standard mixture proportions of highperformance cementitious composites [24], 20\% fly ash, by weight of the total mass of the cementitious materials, was used to replace some cement. The fly-ash additive was necessary to maintain the fluidity of the mortar. The dosages of GO were arbitrarily selected as $0.00 \%\left(0.000 \mathrm{~kg} \mathrm{~m}^{-3}\right), 0.02 \%\left(0.157 \mathrm{~kg} \mathrm{~m}^{-3}\right)$, $0.04 \%\left(0.314 \mathrm{~kg} \mathrm{~m}^{-3}\right), 0.06 \%\left(0.472 \mathrm{~kg} \mathrm{~m}^{-3}\right), 0.08 \%$ $\left(0.629 \mathrm{~kg} \mathrm{~m}^{-3}\right)$, and $0.10 \%\left(0.786 \mathrm{~kg} \mathrm{~m}^{-3}\right)$, respectively, measured and quantified as a function of the total mass of the cementitious materials, namely cement and fly ash (i.e. weight of $\mathrm{GO}$ divided by the weight sum of cement plus fly ash). As shown in Table 3, the CNTs content was maintained constant at $0.15 \%\left(1.179 \mathrm{~kg} \mathrm{~m}^{-3}\right)$ by total weight of the cementitious materials, namely cement and fly ash, i.e., weight of CNTs divided by the weight sum of cement plus fly ash $[12,25]$. The cementitious specimens were demolded $24 \mathrm{~h}$ after forming and cured for different time periods ranging from 3 to 28 days in a standard curing room with a relative humidity of about $95 \%$ at $20 \pm 2{ }^{\circ} \mathrm{C}$ prior to testing [26]. Three replicate specimens were molded and tested per material per $\mathrm{GO} /$ CNTs dosage per curing age per test condition.

\subsection{Laboratory testing methods}

The laboratory tests conducted in this study are discussed in this subsection and including the following: workability, mechanical properties, frost resistance, and water impermeability.

\subsubsection{Workability test}

The fresh mortar was poured into round table test molds with an upper diameter of $70 \mathrm{~mm}$, a lower diameter of $90 \mathrm{~mm}$, and a height of $60 \mathrm{~mm}$ in two lifts. After the first installation to a height of $2 / 3$ of the mold, the mortar was compacted with the same compactive-effort for each lift. Then, the fresh mortar was poured into the test mold with the surface slightly higher than the top of the mold and the compaction process was repeated. After compaction, the sleeve at the upper part of the test mold was grounded to ensure surface smoothness. Finally, the round table test mold was gently lifted along the vertical direction. The maximum expansion and vertical direction diameters of mortar were measured on a vibration table with a ruler after 25 times of vibrations. For determining fluidity, the time from mixing mortar to the expansion diameter measurement of the mini slump was $6 \mathrm{~min}$. The slump expansion was determined using Eq. (1):

Mini-slump expansion $=\left(d_{1}+d_{2}\right) / 2$

where $d_{1}=$ maximum expansion direction diameter and $\mathrm{d}_{2}=$ maximum extension direction vertical diameter, respectively. Three replicate specimens were evaluated for workability per $\mathrm{GO}$ dosage.
Table 3 Mixture proportions of $\mathrm{GO} / \mathrm{CNTs}$ cement composites $\left(\mathrm{kg} \mathrm{m}^{-3}\right)$

\begin{tabular}{llllllll}
\hline Number & Cement & Fly ash & Water & Sand & $\begin{array}{l}\text { Super-plasti- } \\
\text { cizer }\end{array}$ & GO & CNTs \\
\hline OPC & 629 & 157 & 236 & 1218 & 1.57 & 0 & 1.179 \\
GO-002 & 629 & 157 & 236 & 1218 & 1.57 & 0.157 & 1.179 \\
GO-004 & 629 & 157 & 236 & 1218 & 1.57 & 0.314 & 1.179 \\
GO-006 & 629 & 157 & 236 & 1218 & 1.57 & 0.472 & 1.179 \\
GO-008 & 629 & 157 & 236 & 1218 & 1.57 & 0.629 & 1.179 \\
GO-010 & 629 & 157 & 236 & 1218 & 1.57 & 0.786 & 1.179 \\
\hline
\end{tabular}




\subsubsection{Mechanical property tests}

The size of the cubical specimens for the compressive tests was $50 \mathrm{~mm}$. The size of the three-point bending test beam specimens was $20 \mathrm{~mm}$ in width $\times 20 \mathrm{~mm}$ in thickness $\times 90 \mathrm{~mm}$ in length. All the specimens, three replicates per $\mathrm{GO}$ dosage per test type, were tested after 28 days of curing in a $95 \%$ relative humidity room at $20 \pm 2{ }^{\circ} \mathrm{C}$.

The compression test was conducted using the flexural compression tester. During the whole loading process, the specimens were monotonically loaded uniformly at a rate of $0.6 \mathrm{kN} \mathrm{s}^{-1}$ until failure. The average values of the maximum load, for three replicate specimens, were taken as the test values for each group, i.e., GO dosage. The three-point bending test was conducted using the material test system (MTS) device (C43.304, USA) at a monotonic loading rate of $0.1 \mathrm{~mm} \mathrm{~min}^{-1}$.

\subsubsection{Frost resistance test}

In accordance with the Chinese specification JGJ/T 70-2009 [27], the frost resistance of $70.7 \mathrm{~mm} \times 70.7 \mathrm{~mm} \times 70.7 \mathrm{~mm}$ cubical mortar specimens was tested by freezing and thawing for 300 cycles. Four specimen groups were used and Ordinary Portland Cement concrete (OPC) was used as the control compressive strength test specimens for antifreezing at the same age. After $24 \mathrm{~h}$ of pouring and forming, demolding was carried out. The cubical mortar specimens were then put into a $20 \pm 2{ }^{\circ} \mathrm{C}$ water-bath for 2 days after 26 days of standard curing [26]. The cubical mortar specimens were then weighed after drying. The freeze-thaw test specimens were put into the freezer while the control specimens were put into a standard curing box until the end of the freeze-thaw cycle.

During the freezing process, the specimens were conditioned and controlled at a temperature of $-20 \pm 2{ }^{\circ} \mathrm{C}$. Thereafter, the specimens were put in $+20 \pm 2{ }^{\circ} \mathrm{C}$ waterbath for thawing immediately after freezing for $4 \mathrm{~h}$. After thawing, the specimens were subjected to the next cycle and so forth. The appearance of damage and the dry weight of the specimens were recorded during the $5,20,50,100$, 150 , and 300 freeze-thaw cycles. In the control group, the specimens were soaked in water for 2 days before the end of 150 and 300 freeze-thaw cycles, respectively. Three replicate specimens were used per $\mathrm{GO}$ dosage (i.e., per group). The mass-loss rate of the specimen after freeze-thaw cycles was computed using Eq. (2).

$\Delta m_{m}=\frac{m_{0}-m_{n}}{m_{0}} \times 100 \%$

where $\Delta m_{m}=$ the mass loss rate after $n$ freeze-thaw cycles based on three replicate specimens, $m_{0}=$ mass of the test specimen before the freeze-thaw cycle test (g); and $m_{n}=$ mass of the test specimen after $n$ freeze-thaw cycles (g).

\subsubsection{Impermeability test}

In this study, the impermeability test was accomplished using both the impermeable marking and penetration depth methods-using a minimum of three replicate specimens per test method per GO dosage/group. These two laboratory test methods are discussed in the subsequent text.

\section{Impermeable marking method}

As discussed and illustrated subsequently, this method measures and quantifies water impermeability based on the water pressure concept [28]. A mortar mold with an upper diameter of $70 \mathrm{~mm}$, a lower diameter of $80 \mathrm{~mm}$, and a height of $30 \mathrm{~mm}$ was used to fabricate six test specimens per $\mathrm{GO}$ dosage. After putting the mixed mortar into the test mold, the plasterer was evenly inserted and vibrated for 35 times. The molds were then trimmed to ensure surface smoothness. After $24 \mathrm{~h}$, the demolded specimens were kept in the curing box for 28 days. Thereafter, one side of the specimens with a dry surface was rolled in melted paraffin followed by complete sealing in a preheating test mold. After cooling to room temperature, the specimens were installed into an SS-1.5 mortar permeameter (Shanghai Dongxing Building Materials Test Equipment Co., Ltd.) (Fig 1a) for the water impermeability test.

During the impermeability test, the specimens were pressurized from 0.2 to $0.3 \mathrm{MPa}$-in particular with no water seepage under $0.2 \mathrm{MPa}$ for $2 \mathrm{~h}$. The pressure was increased by $0.1 \mathrm{MPa}$ every $1 \mathrm{~h}$. The pressure $H$ was recorded when water seepage appeared in all the specimens. If the specimens were impermeable after being pressurized to $1.5 \mathrm{MPa}$, they were taken out from the impermeability tester and placed under normal pressure for $6 \mathrm{~h}$. A steel cushion strip with a diameter of $6 \mathrm{~mm}$ was placed at the center of the upper and lower end faces of the test specimen. After splitting the test specimen into two halves along the vertical section, the watermark on the split surfaces was immediately traced using a waterproof pen. Then, a prefabricated trapezoidal transparent plastic plate was placed on the split surface to measure the distance from the bottom to the intersection of the water (Fig. 1b). Eight vertical lines were measured using a steel ruler to $1 \mathrm{~mm}$ accuracy. The arithmetic average height from upper to the lower ends of the aggregates was taken as the water penetration height if the measuring point was blocked. An average value of eight seepage heights was 
$\mathbf{a}$

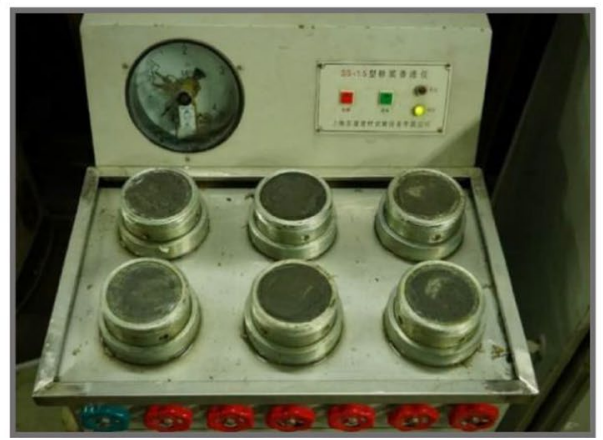

b

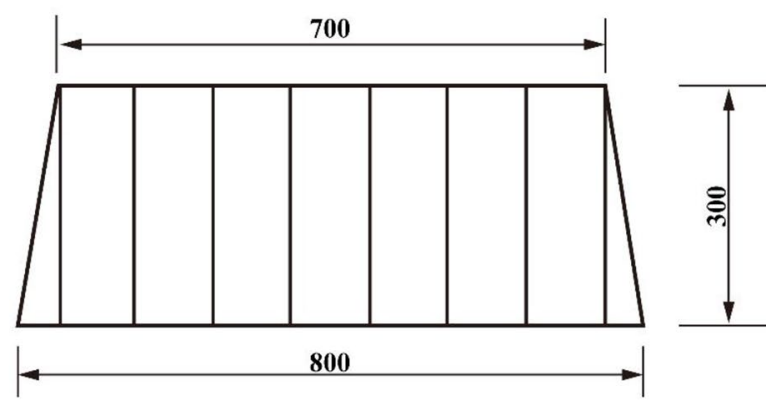

Fig. 1 a Mortar impermeability tester; $\mathbf{b}$ schematic diagram of transparent plastic plate

taken as the penetration depth for each specimen. The impermeability pressure was calculated and determined using Eq. (3).

$P=H-0.1$.

In Eq. (3), $P$ is the impermeability pressure of the mor$\operatorname{tar}(\mathrm{MPa})$, accurate to $0.1 \mathrm{MPa}$ and $H$ is the water pressure $(\mathrm{MPa})$ in case of water seepage in three of six test specimens.

\section{Penetration depth method}

One specimen from each $\mathrm{GO}$ dosage group was put on the mortar impermeability tester under a $0.2 \mathrm{MPa}$ pressure. The pressure increased to $0.3 \mathrm{MPa}$ when there is no water seepage after $2 \mathrm{~h}$. After $1 \mathrm{~h}$, the pressure was increased to $0.4 \mathrm{MPa}$ for $1 \mathrm{~h}$. Thereafter, the mortar impermeability tester was closed after $1 \mathrm{~h}$ at constant pressure, with specimen and the specimen whilst still impermeable under 1.5 MPa pressure. The specimen was immediately split under a pressure machine and the seepage height of each specimen was measured. The permeability coefficient was calculated using Eq. (4).

$K_{p}=\frac{h^{2} v}{2 t \Delta P}$

where $K_{p}=$ permeability coefficient, $\mathrm{h}=$ average penetration depth, $v=$ porosity of test piece, and $t=$ test time for applying pressure. Because it is difficult to measure the porosity of the whole specimen, Eq. (5) was used to compute $v$.

$v=\frac{V_{w}}{A h}$

where $V_{w}=$ volume of the water penetrating into the test piece and $A=$ cross sectional area of the specimen. The volume of water infiltrated into the specimen can be used to estimate the mass of the test specimen before and after the test ( $m_{0}$ and $m$ ) using Eqs. (6) and (7).

$\Delta m=m-m_{0}$

$V_{m}=\Delta m / \rho_{\text {water }}$

\section{Laboratory test results, analysis, and discussions}

The laboratory test results are presented, analyzed, and discussed below. The test results include workability, mechanical properties, frost resistance, and impermeability, which are based on a minimum of three replicate specimens per test type per $\mathrm{GO}$ dosage/group.

\subsection{Effects of GO/CNTs on the mixture workability}

By investigating the effects of GO and CNTs on the fluidity of the mortar, it was found that the fluidity of mortar decreased significantly with an increase in the GO content. The slump of the mortar decreased by about $30.9 \%$ in the presence of $0.08 \% \mathrm{GO}$ comparing to that of the OPC group (i.e., $13 \mathrm{~mm}$ vs. $18.8 \mathrm{~mm}$ ). However, no significant change was observed with an increase in the $\mathrm{GO}$ content beyond $0.08 \%$, i.e., Fig. 2a shows a gentle slope change after the $0.08 \% \mathrm{GO}$ mark. The slurry precipitation from the bottom significantly reduced after adding GO and CNTs when lifting the slump expansion platform (Fig. 2a, b). There was no slurry precipitation in the presence of $\mathrm{GO}$ below $0.04 \%$. Moreover, the mortar could not be vibrated and compacted when the content of $\mathrm{GO}$ was less than $0.08 \%$. These results demonstrated that the dispersion of $\mathrm{GO}$ and CNTs with large surface area in the cement paste can absorb a large amount of water to significantly increase their wettability, which ultimately improves the water retention 


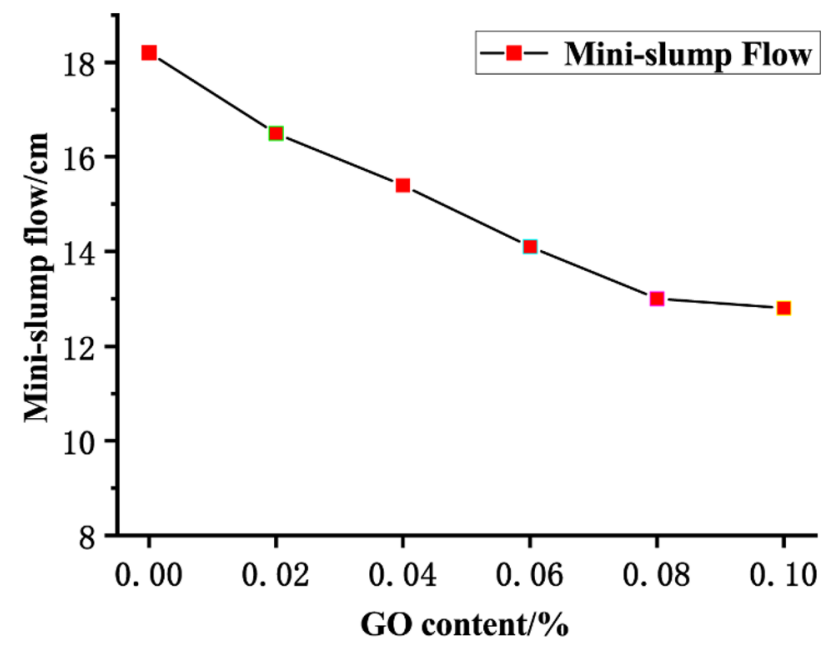

Fig. 2 Effects of GO/CNTs on the mini-slump expansion of mortar

and segregation resistance of the mixture. In addition, the small cement particles assumably adsorbed on the GO and CNTs surfaces improved the adhesion and segregation resistance of the mixture by promoting cement hydration and filling of the micro-pores $[29,30]$.

\subsection{Effect of fly ash on the mixture workability}

It has been reported that the "ball effect" of fly ash can partially alleviate the adverse effects of poor fluidity caused by $\mathrm{GO}$ and CNTs [31]. The slump expansion of cementitious composites containing $0.03 \% \mathrm{GO}$ increased from 142 to $210 \mathrm{~mm}$ when $20 \%$ fly ash was added. In this study, $20 \%$ fly ash was also used to improve the fluidity of the mortar. The mini-slump expansion results of the cementitious composites with and without fly ash are shown in Table 4. In the table, the row for "Unsubstituted (U)" represents the mortar's mini-slump expansion when fly ash was not used to replace cement while the row for "Replacement of 20\% fly ash (R)" represents the mortar's mini-slump expansion when fly ash was used to replace $20 \%$ of cement. The relative value in the last row is the quotient of the mini-slump expansion of "Replacement of $20 \%$ fly ash (R)" and "Unsubstituted $(\mathrm{U})$ ", i.e., relative vale $=\mathrm{R} / \mathrm{U}$ as a percentage ratio.
As theoretically expected, the introduction of fly ash improved the slump expansion of cement composites by $30-40 \%$. This result demonstrated that the spherical and smooth fly ash particles can drive the slurry flow after wetting. Furthermore, fly ash can increase the contact area between slurry and aggregates, fill the gap between sand and stone, which finally yields in an improved workability for the cementitious composite (mixture). In addition, fly ash can also reduce the friction between the cement-mortar viscosity and particles by facilitating uniform dispersion of the cement particles. Furthermore, fly ash can also improve the workability of the mortar with high contents of GO and CNTs by enhancing the bleeding and the cohesion property of the cementitious composites.

\subsection{Effects of GO/CNTs on the mechanical properties of the mixture}

Table 5 and Fig. 3a shows the compressive strength results as a function of the $\mathrm{GO}$ content and curing time. For each curing age, the compressive strength in Fig. 3a shows an increasing trend up to a certain $\mathrm{GO}$ dosage and thereafter, a decline. The highest compressive strengths occurred at $0.06 \% \mathrm{GO}$ with $28.4 \mathrm{MPa}$ and $46.0 \mathrm{MPa}$ respectively, at the early stages of 3 days and 7 days curing, respectively, which are $64.16 \%$ and $45.57 \%$ higher than that of the control without GO/CNTs (i.e., 28.4 MPa vs. 17.3 MPa and 46.0 MPa vs. $31.6 \mathrm{MPa}$, respectively). This result (i.e., gain in compressive strengths) evidently demonstrated significant strengthening effects of GO and CNTs on cementitious materials in the early stages of curing.

In Fig. 3a, the compressive strength of the specimen with $0.08 \%$ GO is the largest, about $41.15 \%$ higher than that of control without GO/CNTs at the $28 \mathrm{~d}$ curing period (i.e., $61.4 \mathrm{MPa}$ vs. $43.5 \mathrm{MPa}$ ). By contrast, the compressive strength decreased to about $50 \mathrm{MPa}$ at $0.10 \% \mathrm{GO}$ dosage. These results can be explained that excessive $\mathrm{GO}$ in the presence of CNTs increased the number of harmful holes in the specimen by reducing the fluidity of the mortar, which ultimately caused a decay in the compressive strength $[32,33]$. Additionally, the agglomeration and coalescence of excess GO and CNTs also probably affected the
Table 4 Slump expansion before and after $20 \%$ fly ash

\begin{tabular}{|c|c|c|c|c|c|c|}
\hline \multirow[t]{2}{*}{$\mathrm{GO}$ content $\left(\mathrm{kg} \mathrm{m}^{-3}\right)$} & $0.00 \%$ & $0.02 \%$ & $0.04 \%$ & $0.06 \%$ & $0.08 \%$ & $0.10 \%$ \\
\hline & $(0.000)$ & $(0.175)$ & $(0.314)$ & $(0.472)$ & $(0.629)$ & $(0.786)$ \\
\hline \multirow[t]{2}{*}{ CNTs content $\left(\mathrm{kg} \mathrm{m}^{-3}\right)$} & $0.15 \%$ & $0.15 \%$ & $0.15 \%$ & $0.15 \%$ & $0.15 \%$ & $0.15 \%$ \\
\hline & $(1.179)$ & (1.179) & $(1.179)$ & $(1.179)$ & $(1.179)$ & $(1.179)$ \\
\hline Unsubstituted, U (mm) & 182 & 165 & 154 & 141 & 130 & 128 \\
\hline $\begin{array}{l}\text { Replacement of } 20 \% \text { fly ash, } \\
\text { R (mm) }\end{array}$ & 235 & 214 & 205 & 196 & 177 & 168 \\
\hline Relative value (R/U) (\%) & 129.12 & 129.70 & 133.12 & 139.01 & 136.15 & 131.25 \\
\hline
\end{tabular}


Table 5 Compressive strength results at 3,7 , and 28 days curing periods

\begin{tabular}{|c|c|c|c|c|c|c|}
\hline \multirow[t]{2}{*}{ Number } & \multicolumn{2}{|l|}{$3 d$} & \multicolumn{2}{|l|}{$7 d$} & \multicolumn{2}{|l|}{$28 d$} \\
\hline & Intensity (MPa) & Relative (\%) & Intensity (MPa) & Relative (\%) & Intensity (MPa) & Relative (\%) \\
\hline OPC & 17.30 & 100.00 & 31.60 & 100.00 & 43.50 & 100.00 \\
\hline GO-002 & 22.00 & 127.17 & 34.80 & 110.13 & 46.30 & 106.44 \\
\hline GO-004 & 27.20 & 157.23 & 37.20 & 117.72 & 53.50 & 122.99 \\
\hline GO-006 & 28.40 & 164.16 & 46.00 & 145.57 & 56.30 & 129.43 \\
\hline GO-008 & 25.20 & 145.66 & 42.80 & 135.44 & 61.40 & 141.15 \\
\hline GO-010 & 24.80 & 143.35 & 40.60 & 128.48 & 52.20 & 120.00 \\
\hline
\end{tabular}
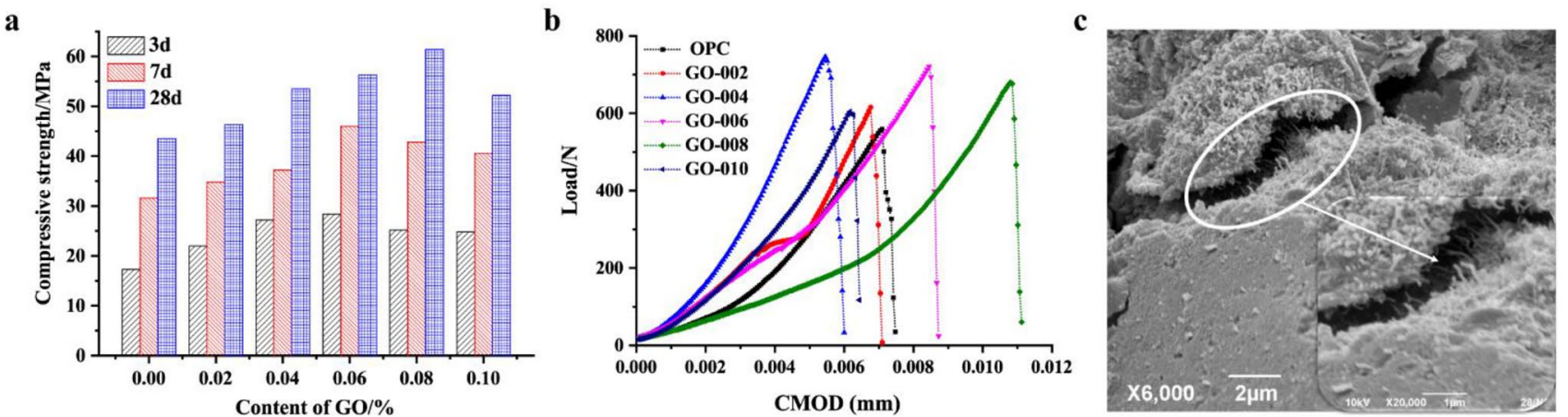

Fig. 3 a Compressive strength versus GO content; $\mathbf{b}$ load-deflection curve; c SEM image of separated CNTs

compressive strength by increasing the internal defects of the specimens during the agitation process.

By conducting the three-point bending test on the MTS device, load-deflection curves of the cementitious composites with different GO contents were generated as shown in Fig. 3b. Among the dosages evaluated, $0.04 \%$ (GO-004) and $0.06 \%$ (GO-006) of GO showed the best strengthening effect, which are comparable to the $0.08 \%$ (GO-008) curve with nearly the same ultimate load (Fig. 3b). These results could suggest that $0.04-0.06 \%$ GO could be the optimum $\mathrm{GO}$ dosage range for both rapid strength gain and achieving maximum ultimate load failure. However, the crack opening distance increased with an increase in the GO content, which suggested increased brittleness and deformation in the specimens. Due to the small cross-sectional size of the specimens and the rapid loading rate, the declining response of the curve after the peak load is not fully reflected in Fig. $3 \mathrm{~b}$.

With respect to bending resistance, $0.15 \%$ CNTs exhibited the greatest influence. Scanning electron microscope (SEM) images in Fig. $3 \mathrm{c}$ indicates that CNTs had completely separated. It has been reported in the literature [34] that the strength and toughness of the cementitious composites are not only closely related to the interface bonding between the reinforcement and the cementitious matrix but also related to the strength and toughness of the reinforcement itself. Since the oxygen-containing functional groups on the multi-wall CNTs can react with the cement hydration products, the resultant interface has the potential to efficiently transfer the external forces to induce strengthening and toughening effects on the mixture [35]. However, the interface will disintegrate if the cementitious composite is damaged due to the weak interface bonding between the fiber-reinforced body and the cement matrix. This effect also aided in toughening the cementitious composites [36]. These results show that the strengthening and toughening effects of CNTs are mainly achieved by the main crack turning along the CNTs, namely the bridging effect of CNTs on the cement matrix and the energy consumption of CNTs. Figure 4a shows the spectrum of the specimens for infrared characterization of the $\mathrm{GO}$ / CNTs at 28-day curing period. The infrared spectrum in the range of $600-4000 \mathrm{~cm}^{-1}$ is divided into two bands of $600-2000 \mathrm{~cm}^{-1}$ and $2000-4000 \mathrm{~cm}^{-1}$, respectively, to effectively analyze the effects of GO/CNTs on the hydration products of cement (Fig. 4b, c). The characteristic groups and wavenumbers of hardened cement stones due to $\mathrm{GO} / \mathrm{CNTS}$ additives have been reported in the literature [37-43]. Table 6 lists these characteristic groups and wavenumbers for $\mathrm{O}-\mathrm{H}, \mathrm{H}-\mathrm{O}-\mathrm{H}, \mathrm{Si}-\mathrm{O}$, and $\mathrm{C}-\mathrm{O}$, respectively, that correspond to calcium hydroxide, chemically bound water, calcium silicate hydrate, and calcium carbonate in hardened cement paste, respectively. 


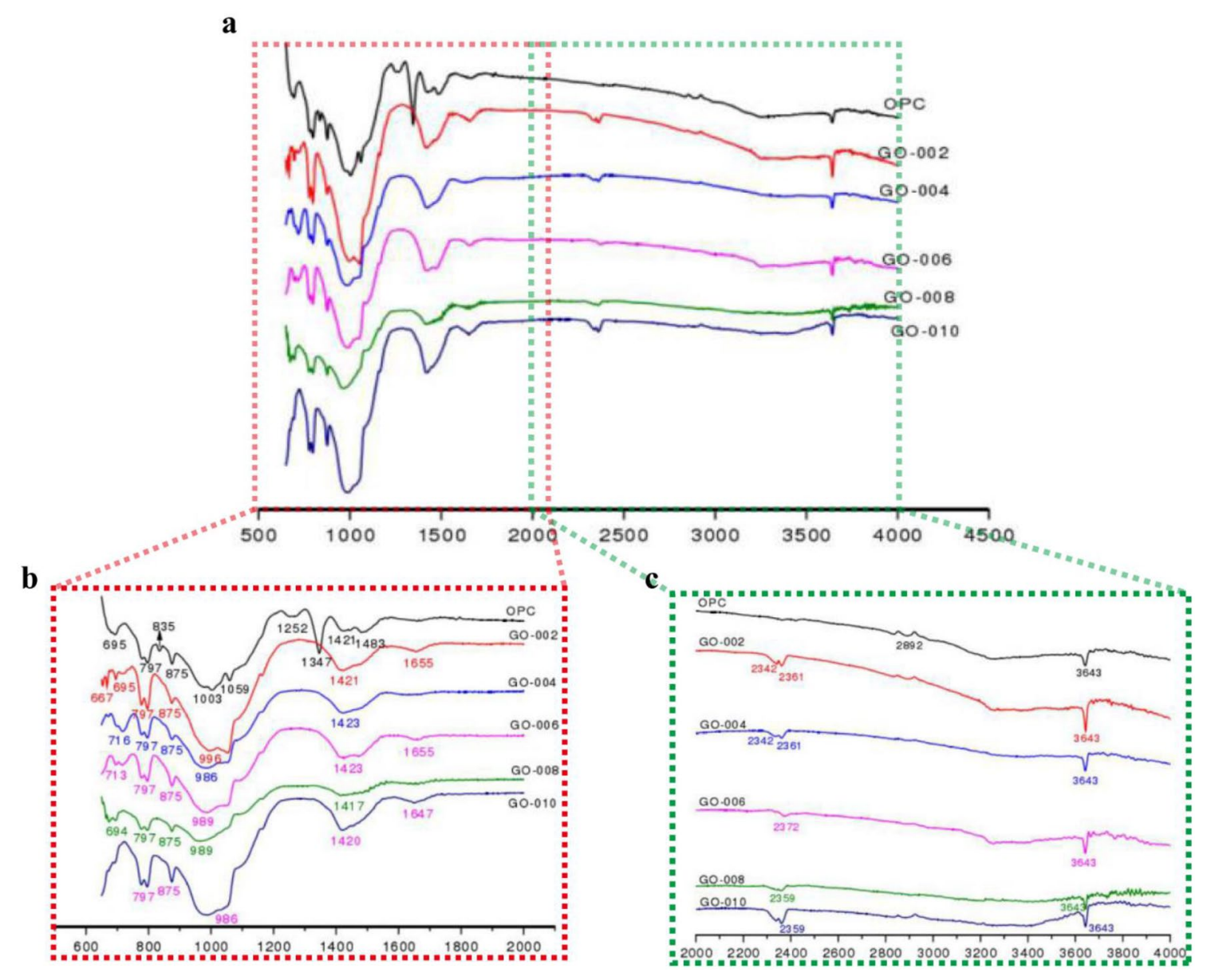

Fig. 4 a Infrared spectrum detection of cementitious materials; $\mathbf{b}, \mathbf{c}$ infrared spectrum characteristic peak analysis

Table 6 Characteristic peak of the groups in hardened cement stone

\begin{tabular}{ll}
\hline Wavenumber $\left(\mathrm{cm}^{-1}\right)$ & Characteristic group \\
\hline 695 & Antisymmetric stretching vibration of $\mathrm{CO}_{3}{ }^{2-}$ in calcium carbonate (v3) \\
840 & $\mathrm{Q}_{1}$ Si-O tetrahedral stretching vibration in un-hydrated cement \\
875 & Plane bending vibration of $\mathrm{CO}_{3}{ }^{2-}$ in calcium carbonate (calcite) (v2) \\
$970-1020$ & Tetrahedron stretching vibration of $\mathrm{Q}_{2} \mathrm{Si}-\mathrm{O}$ in hydrated calcium silicate gel \\
1089 & $\mathrm{Q}_{3} \mathrm{Si}-\mathrm{O}$ stretching vibration in hydrated calcium silicate gel \\
1421 & Antisymmetric stretching vibration of $\mathrm{CO}_{3}{ }^{2-}$ in calcium carbonate (v3) \\
1650 & Bending vibration of $\mathrm{O}-\mathrm{H}$ in chemical binding water (v2) \\
2352 & Antisymmetric stretching vibration of $\mathrm{CO}_{3}{ }^{2-}$ in calcium carbonate (v3) \\
3643 & O-H stretching vibration in calcium hydroxide \\
\hline
\end{tabular}

From Fig. 4b, $c$, it was found that the $\mathrm{O}-\mathrm{H}$ stretching vibration peak in calcium hydroxide appeared near $3643 \mathrm{~cm}^{-1}$. Only in GO-002, the peak became slightly sharp, indicating no effects of GO and CNTs on calcium hydroxide, the hydration product of cement. Interestingly, the characteristic peak of $\mathrm{H}-\mathrm{O}-\mathrm{H} 1640 \mathrm{~cm}^{-1}$ shifted to $1655 \mathrm{~cm}^{-1}$ for GO-002 and GO-006, respectively, and $1647 \mathrm{~cm}^{-1}$ for GO-010 [44]. This result demonstrated that nanomaterial adsorption and adhesion of GO and CNTs yielded in hydration products containing more chemical binding water.

Considering anhydrous calcium carbonate in hardening cement $\mathrm{CO}_{3}{ }^{2-}$, there are five characteristic peaks of vibration in the infrared spectrum region: $695 \mathrm{~cm}^{-1}$, $875 \mathrm{~cm}^{-1}, 1070 \mathrm{~cm}^{-1}, 1425 \mathrm{~cm}^{-1}$, and $2352 \mathrm{~cm}^{-1}$, 
$695 \mathrm{~cm}^{-1}, 875^{-1}$, and $1425 \mathrm{~cm}^{-1}$ corresponding to calcite that was nearly unchanged.

The characteristic peaks of $1059 \mathrm{~cm}^{-1}$ maybe caused by the migration of the characteristic peak of $1070 \mathrm{~cm}^{-1}$ that apparently disappeared when GO and CNTs were added. The $1070 \mathrm{~cm}^{-1}$ reading is probably the cement hydration products of calcium silicate gel carbonization $\left(\mathrm{CO}_{3}{ }^{2-}\right)$ in Q3 anti-symmetric stretching vibration, and oxidization of graphene and CNTs that optimized the pore structurebearing in mind that the $\mathrm{CO}_{2}$ in the air is more difficult to contact with the cement hydration products within the cement. However, the causes and phenomenon of the new characteristic peak at $2352 \mathrm{~cm}^{-1}$ in the OPC specimens after the incorporation of GO and CNTs needs further research.

From Fig. 4, it was also observed that the characteristic peak of $\mathrm{Si}-\mathrm{O}$ in $\mathrm{C}-\mathrm{S}-\mathrm{H}$ of hydrated calcium silicate appeared at near $1000 \mathrm{~cm}^{-1}$. However, the addition of GO and CNTs did not affect the position of the characteristic peak, which demonstrated that GO and CNTs did not change the hydration products of cement. The enhanced toughening mechanism resulted from the change of the hydration process and morphology amalgamation of the cementitious composites. In addition, the characteristic peak of $\mathrm{Si}-\mathrm{O}$ at $835 \mathrm{~cm}^{-1}$ of OPC disappeared after the addition of GO and CNTs due to the strong cement hydration effect. Similarly, the $\mathrm{Si}-\mathrm{C}$ characteristic peak at $1347 \mathrm{~cm}^{-1}$ of OPC disappeared after the addition of GO and CNTs. These results demonstrated that the hydrophilic groups at the edge of GO layer promoted cement hydration by increasing the contact area between cement and water.

\subsection{Frost resistance test results}

The mass-loss rate of the cementitious composites with different GO/CNTs contents was investigated under 0-300 freeze-thaw cycles. Figure $5 \mathrm{a}$ indicated that the mass decreased by $0.2 \%$ after 20 freeze-thaw cycles for the OPC. During the first 50 freeze-thaw cycles, the mass loss showed a decrease-increase trend with an increase of the freeze-thaw cycles. At the end of 300 freeze-thaw cycles, the mass loss rate was $0.8 \%$ for OPC mixture. These data suggested that part of the water infiltrates into the specimen from the pores during the water melting process due to the large number of pores in the OPC. This infiltration of water into the specimen during the air freezing process froze to form a frost heaving pressure, thus expanding the pores or forming more through pores and infiltrating more water during the water melting process of the next freeze-thaw cycle-which subsequently lead to the rise of specimen mass in the early stage of the freeze-thaw cycle. Subsequently, the frost heaving pressure causes the cementitious material on the surface and near the pores to break up and gradually peel off (see Fig. 5), balancing the mass of the water that seeps into the pores. In the process of 50-300 freeze-thaw cycles, more and more damage resulted into a mass loss rate of $0.8 \%$. However, the results indicated that the first 100 freeze-thaw cycles did not significantly change the mass of the specimen for GO/CNTs with mass fractions of $0.04 \%$ and $0.06 \%$, respectively, indicating that an appropriate amount of GO/CNTs improved the pore structure, reduced the pore numbers, and optimized the pore distribution of the cement composites.

The influence of 150 and 300 freeze-thaw cycles on the compressive strength at 28-day was measured under standard curing conditions. Figure $5 \mathrm{~b}$ showed that the cementitious composites reached stable strength at this time point with $1-2 \%$ increase in 1-3 months. The reason for this result may have been that the fine-graded quartz sand in the composite mixture had generated some alkali activity. The CNTs, when dispersed in sodium dodecyl benzene sulfonate (SDBS) contains a lot of $\mathrm{Na}^{+}$, which could have potentially reacted with the alkali aggregates to form an alkali aggregates (in the sand) to form an alkali-silica gel. The expansion of alkali-silica gel with the absorption of water counteracts the strength increase of some cement paste. The strength rate decreased by about $5-10 \%$ after 150 freeze-thaw cycles. However, the strength loss rate gradually decreases from $30.3 \%$ for OPC to $11.5 \%$ of $0.08 \%$ $\mathrm{GO}$ after 300 freeze-thaw cycles. This result demonstrates that GO and CNTs can significantly improve the frost resistance of cementitious composites.

Hole structure analysis was performed using different methods and the results are shown in Fig. 6 . First, the images of the pores were taken at the same position of four sides with the same area $(20 \mathrm{~mm} \times 20 \mathrm{~mm}$ ) (Fig. 6a). Figure $6 \mathrm{~b}, \mathrm{c}$ show the distribution of the apparent hole structure after 300 freeze-thaw cycles. In order to assess the effects of GO and CNTs on the frost resistance of the cementitious composites, the pore structure was quantitatively analyzed using an Image-Pro Plus software. Figure $6 c$ indicates that the OPC group showed a lot of pores after 300 freeze-thaw cycles, extending from local defects to the whole specimen. By contrary, the pore number significantly reduced with an increase of the GO/CNTs additives. The best uniformly distributed pore structure occurred in the presence of $0.06 \% \mathrm{GO}$. In addition to the micro-aggregation and filling effect of fly ash and the nanomaterial filling effects of GO/CNTs, the cementitious composites with good fluidity is easy to vibrate and compact under low GO/ CNTs concentrations. In general, the continued increase in the GO/CNTs content increased the number and diameter of pores by inhibiting mortar fluidity. Thus, the larger pores formed in the molding process were subjected to greater frost heaving pressure during the freeze-thaw cycles. 

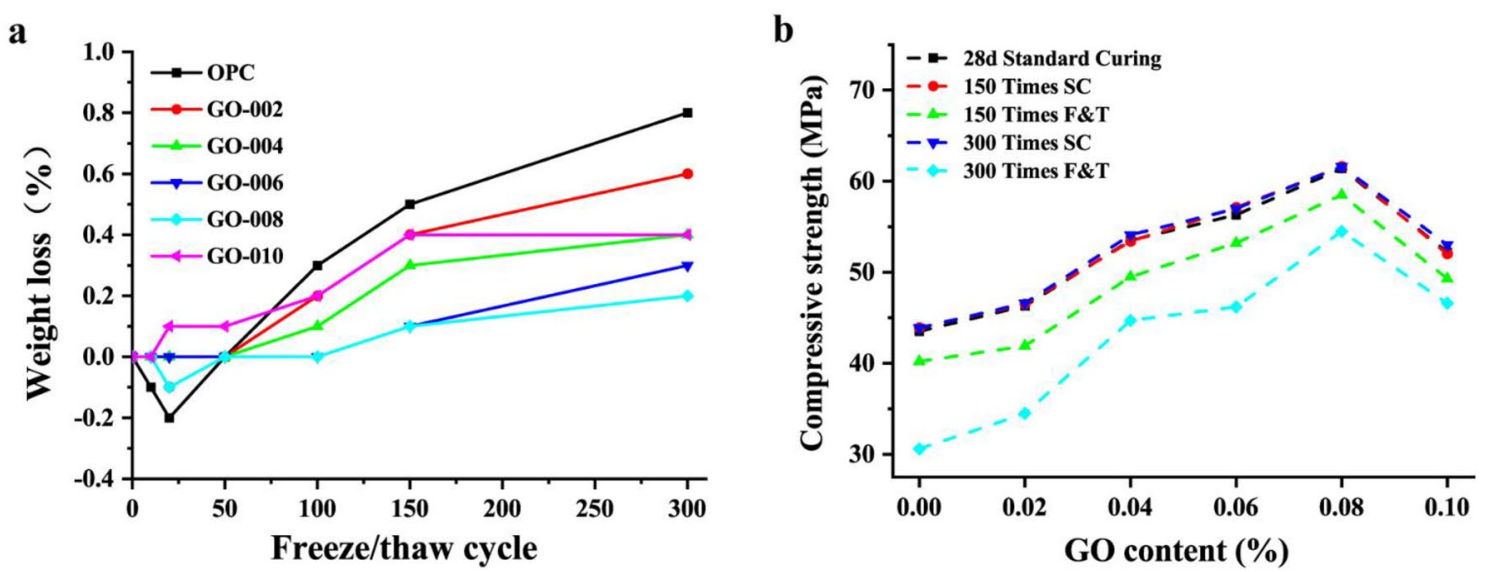

c

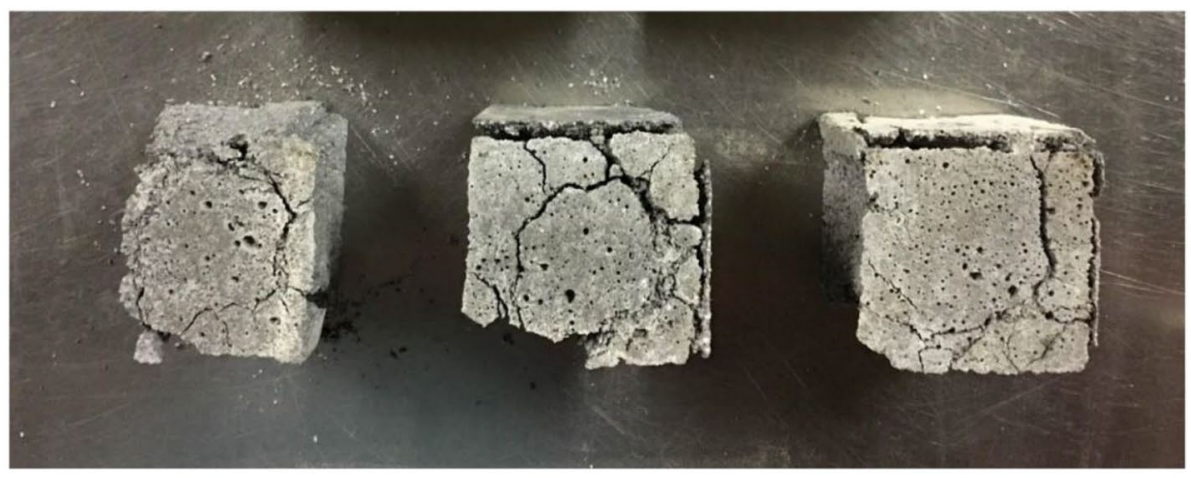

OPC

GO-002

GO-004

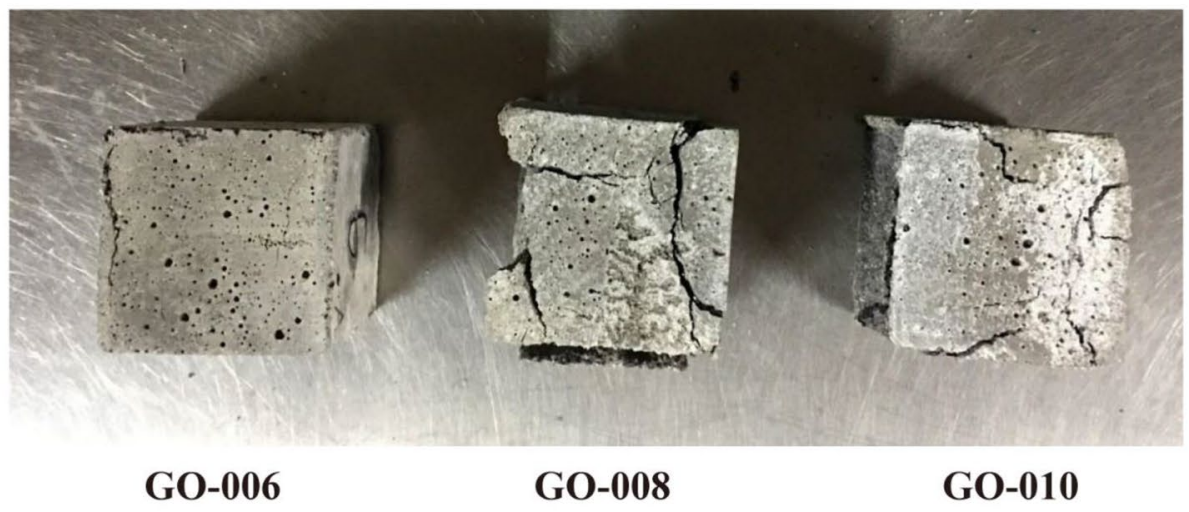

Fig. 5 a Effects of freeze-thawing cycle on mass loss; $\mathbf{b}$ effects of GO content on compressive strength; $\mathbf{c}$ failure modes of specimens under compression after 300 freeze-thaw cycles (SC standard curing; F\&T freeze-thaw)

However, the cementitious composites can form a more compact structure due to the "nucleation" of GO (Fig. 6d). Ultimately, the enhanced strength does not decay easily during the freeze-thaw cycle, resulting in less loss of mass and strength. The originally formed hole can form a closed structure to effectively prevent the penetration of water in the presence of a GO sheet [45]. As depicted in Fig. 6e, SEM images also showed that the two-dimensional GO sheets formed a diaphragm in the hole. Furthermore, the addition of an appropriate amount of GO/CNTs warranted the mass stability under the frost heaving pressure by increasing the strength of cement.

The results of Fig. $6 \mathrm{f}$ shows that the total pore volume of GO-006 is only one-eighth in comparison with the control OPC group. Although the total pore volume of GO-010 is small, the compressive strength is not high because of the high proportion of large pores. Pore diameters larger than $1 \mathrm{~mm}$ are prone to stress concentration and damage, resulting in the loss of mass and strength. The histogram of the pore distribution in Fig. $6 \mathrm{~g}$ indicated that the wide 
range of pore size distribution and large pore numbers for GO-002 exhibited poor frost resistance compared to the OPC group. However, the GO-006 group indicated small pore sizes (under $0.8 \mathrm{~mm}$ ) and optimal pore structure. By contrast, the GO-008 group showed minimal compressive strength loss rate due to the enhancement and toughening effects of $\mathrm{GO}$ and CNTs.

\subsection{Impermeability test results}

Based on the characteristic nature of carbon nanomaterials, permeability was measured using the Permeability Coefficient and Impermeable Marking methods [46]. By assessing and quantifying the influence of GO/CNTs content on the penetration pressure, it was determined that the water pressure strength of the third specimens in each group was $0.5 \mathrm{MPa}, 0.6 \mathrm{MPa}, 1.1 \mathrm{MPa}, 1.5 \mathrm{MPa}, 1.3 \mathrm{MPa}$, and 1.2 MPa, respectively-see Table 7. The impermeability pressure results showed that the water seepage pressure increased first and then decreased with an increase of the GO/CNTs content. The impermeability was the best at $0.06 \%$ GO and $0.15 \%$ CNTs contents with $1.5 \mathrm{MPa}$ seepage pressure. At this condition, the upper surface of the third specimens still did not leak after maintaining a water pressure of 1.5 MPa for $6 \mathrm{~h}$ (Fig. 7a).

Although the permeability coefficient of the cementitious composite is low, it is easy to leak as the pores provided the seepage channel. Therefore, it is necessary to investigate the penetration depth by observing the water penetration by splitting the specimens. The upper surface of the test specimen begins to infiltrate water when the pressure of the control group OPC is $0.4 \mathrm{MPa}$. The whole test specimens were basically in the state of water saturation after splitting. However, the water penetration height decreased after adding GO and CNTs. Due to a lot of localized through holes, the water seepage height in GO-002 and GO-004 is uneven with high and low undulations. However, as the through holes in the test specimens with high GO and CNTs (GO-006, GO-008, and GO-010) reduced, the water seepage height gradually decreased due to the blocking of water seepage channels (Fig. 7b).

Take three specimens from each group (i.e., GO dosage), by selecting eight points on each test specimens and measuring the water penetration height, the average penetration depth of each point was determined as shown in Fig. 7c. Meanwhile, the relevant parameters of the permeability coefficient were calculated by substituting Eqs. (3) and (4), as shown in Table 8. Figure 7d indicated that the permeability coefficient of GO with $0.02 \%, 0.04 \%, 0.06 \%$, $0.08 \%$ and $0.10 \%$ is $36.8 \%, 31.6 \%, 5.3 \%, 10.5 \%$, and $15.8 \%$, respectively, comparing with that of the OPC group. As the permeability mainly depends on the internal pores and cracks of the cementitious composites, GO and CNTs can significantly reduce the permeability coefficient of the test specimens. For ordinary concrete, the permeability of cement hydration products is only $1 / 20-1 / 100$ of the whole cement paste. Therefore, water or harmful gases mainly penetrate through the pores of the cement paste and the contribution of cement hydrates such as gel pores in calcium silicate gel to water penetration can be optimized. For the ultra-high-performance cementitious composites with small porosity, the gel holes provide seepage channels. In this condition, the hydration degree has a significant effect on the permeability of the cement paste.

Although some studies have shown that the increase of porosity can enhance the permeability of concrete, the permeability of concrete with the same porosity is different $[47,48]$. Sometimes, the inverse relationship between them (i.e., porosity vs. permeability) showed the dependence of concrete permeability on the internal porosity, the connection and twists and turns of the cracks. Only connected pores and cracks can become a seepage channel for water. Based on the results of the pore structural analysis and permeability coefficient, six groups of the test specimens can be divided into the following three categories:

1. Large porosity and high permeability The continuous capillary network of OPC group with large porosity and interconnected pores becomes the water seepage channel. Water fills the pores quickly and transfers water pressure to the gel pores under pressure, thereby reducing the water permeability of the cementitious composites (Fig. 7e).

2. Small porosity and low permeability The small pores of GO-006 resemble inner spherical orifices or tubular in morphology. The pores, which are difficult for water to pass through, showed good resistance to water penetration. However, the nucleation effect of GO and CNTs improved the pore structure to a certain extent (Fig. 7f). As shown in the figure, GO can regulate the spatial distribution of the cement hydration products into the smaller pore size of the joint holes, so that calcium silicate hydrate can form a dense cement paste structure by using $\mathrm{GO}$ as core to block the bleeding channels and increase the tortuosity of the permeation path. It has been reported in the literature [49] that the most important influencing factor on the concrete permeability is the critical pore size-that is, the largest pore level of each pore can connect to the larger pores.

3. Large porosity and low permeability (Fig. 7g) The pores of GO-010 are internal spherical or tubular in morphology without any interconnections. The decrease of mixture workability under high GO/CNTs content resulted in the easy production of bubbles, which 

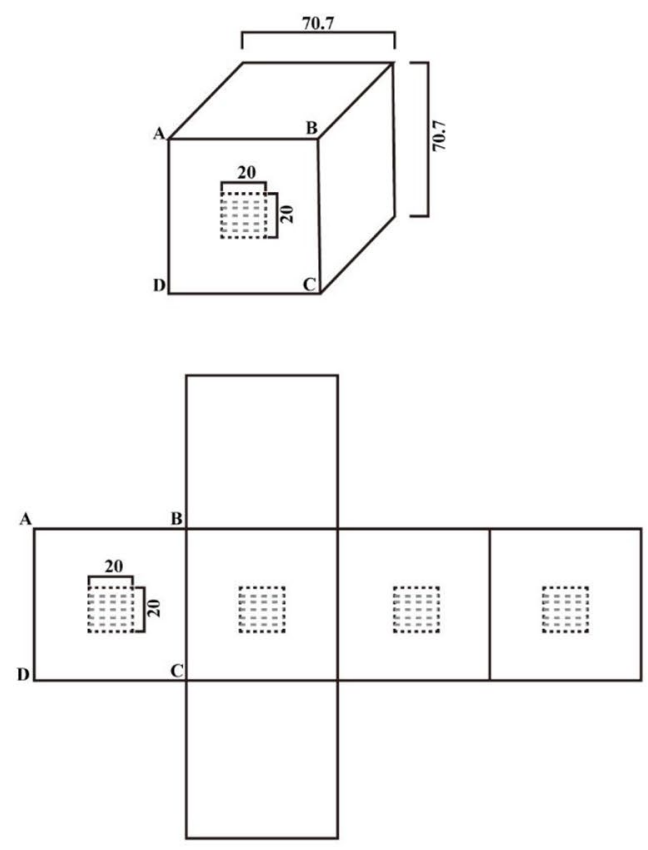

b
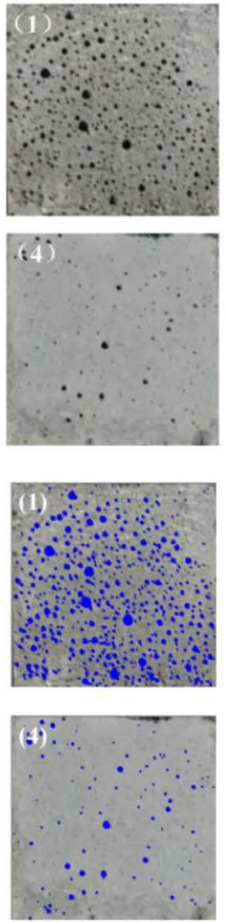
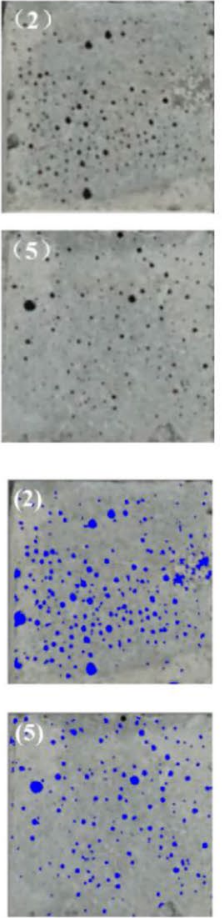
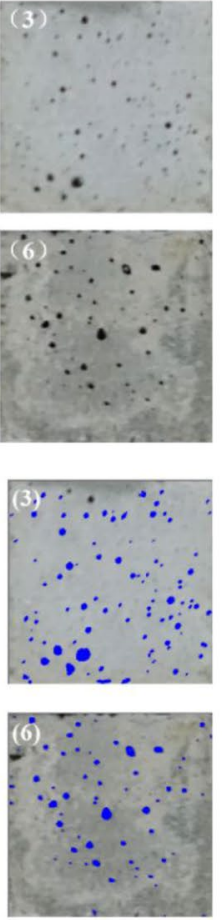

d
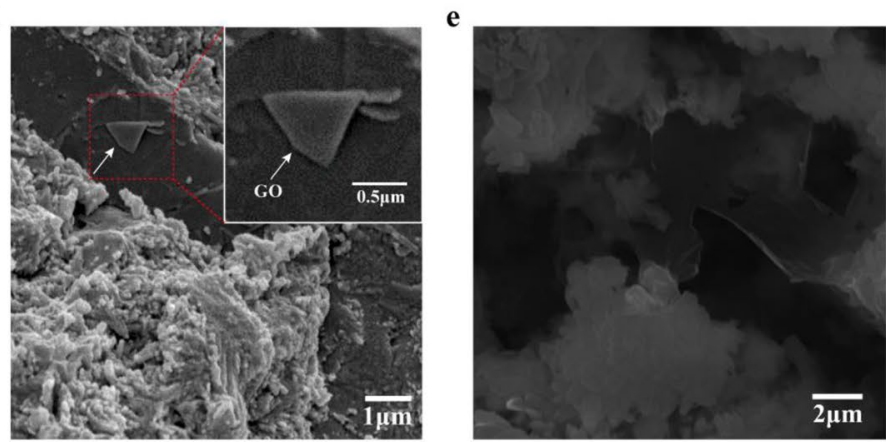

g
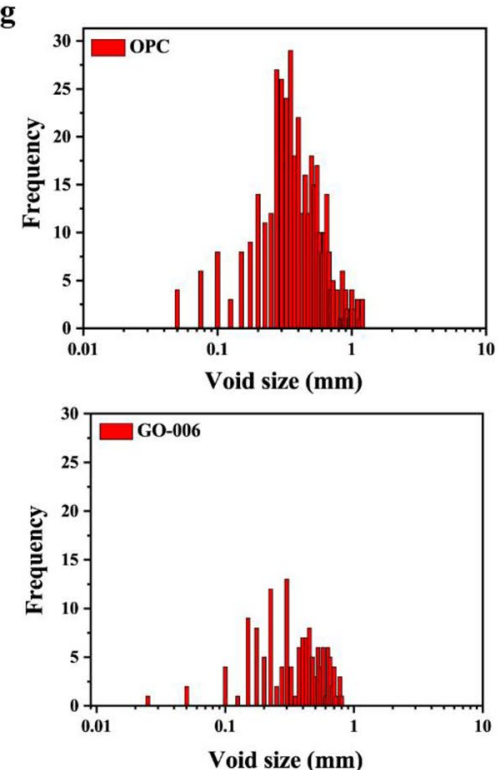

f

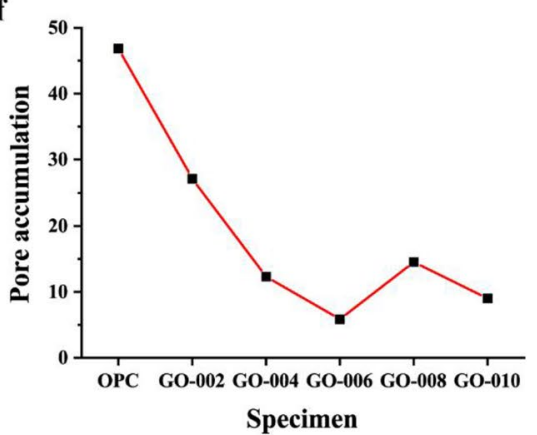

Specimen
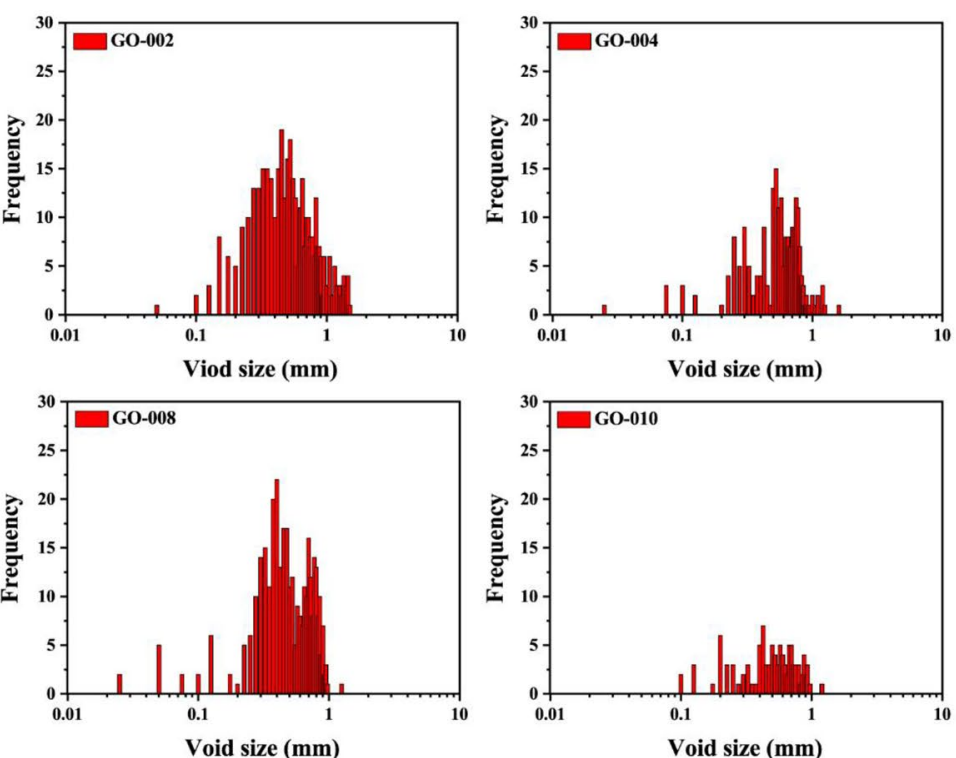
4Fig. 6 a Schematic diagram of the hole structure analysis; $\mathbf{b}$ surface imaging of 300 specimens after freeze-thaw cycles (1-6 represents OPC/GO-002/GO-004/GO-006/GO-008/GO-010); c image pore structure of 300 plus treated specimens after freeze-thaw cycles (1-6 represents OPC/GO-002/GO-004/GO-006/GO-008/GO-010); d SEM of GO in cementitious materials; e SEM image of GO distribution in the hole; $\mathbf{f}$ pore accumulation of specimens; $\mathbf{g}$ pore distribution of specimens after 300 freeze-thaw cycles

cannot be discharged in the process of stirring and vibrating. Finally, large closed pores are formed in the cementitious composites. In addition, the agglomeration and coalescence of GO/CNTS at high contents increase the possibility of internal pore formation. However, the nucleation of GO and CNTs can seal or block these pores. Therefore, although the total porosity of the cement stone could be larger, the smaller opening of porosity and the larger porosity of the tortuous rate showed better permeability resistance.

\section{Conclusions}

This laboratory study investigated the effects of Graphene oxide (GO) and Carbon Nanotubes (CNTs) on workability, compressive strength, frost resistance, and water impermeability of cementitious composites. In the composite mixture, the content of CNTs was $0.15 \%$ (by mass of cementitious materials, namely cement and fly ash), and the content of $\mathrm{GO}$ was $0.00 \%, 0.02 \%, 0.04 \%, 0.06 \%, 0.08 \%$ and $0.10 \%$ (also by mass of cementitious materials, namely cement and fly ash). The key findings and conclusions drawn from the study are summarized below.

GO and CNTs can reduce the fluidity of fresh mortar, which in this study was mitigated by the using of $20 \%$ fly ash (i.e., $20 \%$ by mass of cementitious materials). The compressive strength and flexural toughness exhibited an increasing trend followed by a decline with the increase of the GO/CNTs content. The results of the mechanical properties test showed that enhancement of the early compressive strength ( 3 days and 7 days) of cementitious composites was best when GO content was $0.06 \%$, reaching $28.4 \mathrm{MPa}$ and $46.0 \mathrm{MPa}$, respectively. When the GO content was $0.08 \%$, the 28 days compressive strength reached a maximum of $61.4 \mathrm{MPa}$. As the content of $\mathrm{GO}$ increased to $0.10 \%$, the compressive strength of cementitious composites gradually declined, suggesting that the optimum $\mathrm{GO}$ dosage was around $0.06 \%$ (by mass of the cementitious materials).

The frost resistance test results also revealed that $\mathrm{GO}$ / CNTs additives can significantly enhance the freeze-thawing resistance of the cementitious composites, including reducing the mass-loss rate and strength-loss rate. After 300 freeze-thaw cycles, the minimum mass-loss, and strength-loss rates ( $0.2 \%$ and $11.5 \%$ respectively) occurred when the GO content was $0.08 \%$, with a CNTs content of $0.15 \%$. Hole structure analysis results showed that the total pore volume decreased first and then increased with an increase in the GO content after 300 freeze-thaw cycles. When the GO content was $0.06 \%$, the total pore volume and pore diameter were the smallest, and almost all of the apertures were less than $0.8 \mathrm{~mm}$. However, when the GO content was $0.08 \%$ and $0.10 \%$, respectively, a small number of undesired pores with a pore size greater than $1 \mathrm{~mm}$ appeared.

Lastly, the study indicated that GO and CNTs can significantly reduce the water permeability of cementitious composites. The water permeability of cementitious composites was found not to depend on porosity alone, but on both the porosity and pore structure. With an increase in the GO and CNTs content, the specimens changed from large porosity and high permeability to small porosity and low permeability, and then to large porosity and low permeability, respectively.
Table 7 Effect of different amount of GO/CNTs on water penetration pressure

\begin{tabular}{lcccccc}
\hline $\begin{array}{l}\text { Seepage pressure } \\
\text { (MPa) }\end{array}$ & A & B & C & D & E & F \\
\hline OPC & & 0.4 & & 0.5 & 0.5 & \\
GO-002 & 0.3 & 0.5 & & & & 0.6 \\
GO-004 & & & 0.5 & & 1 & 1.1 \\
GO-006 & & 1.1 & & & & 1.5 \\
GO-008 & 0.8 & & & 1.2 & & 1.3 \\
GO-010 & 0.6 & 1.0 & 1.2 & & & \\
\hline
\end{tabular}




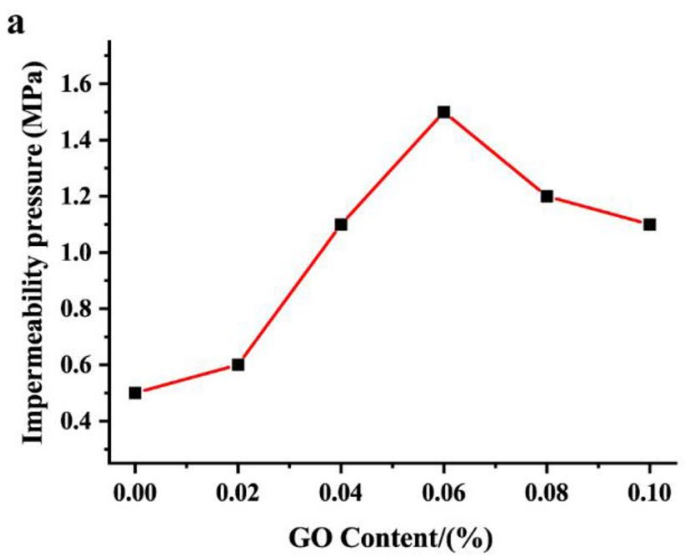

b
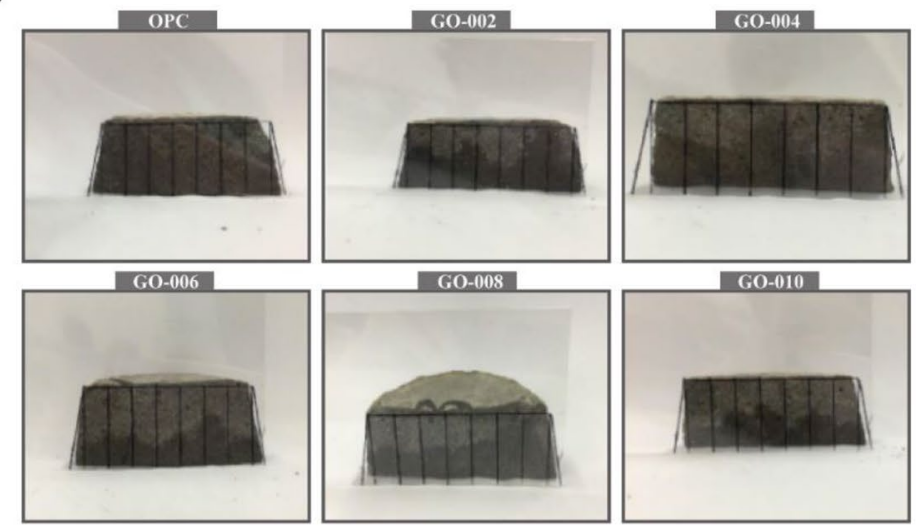

c
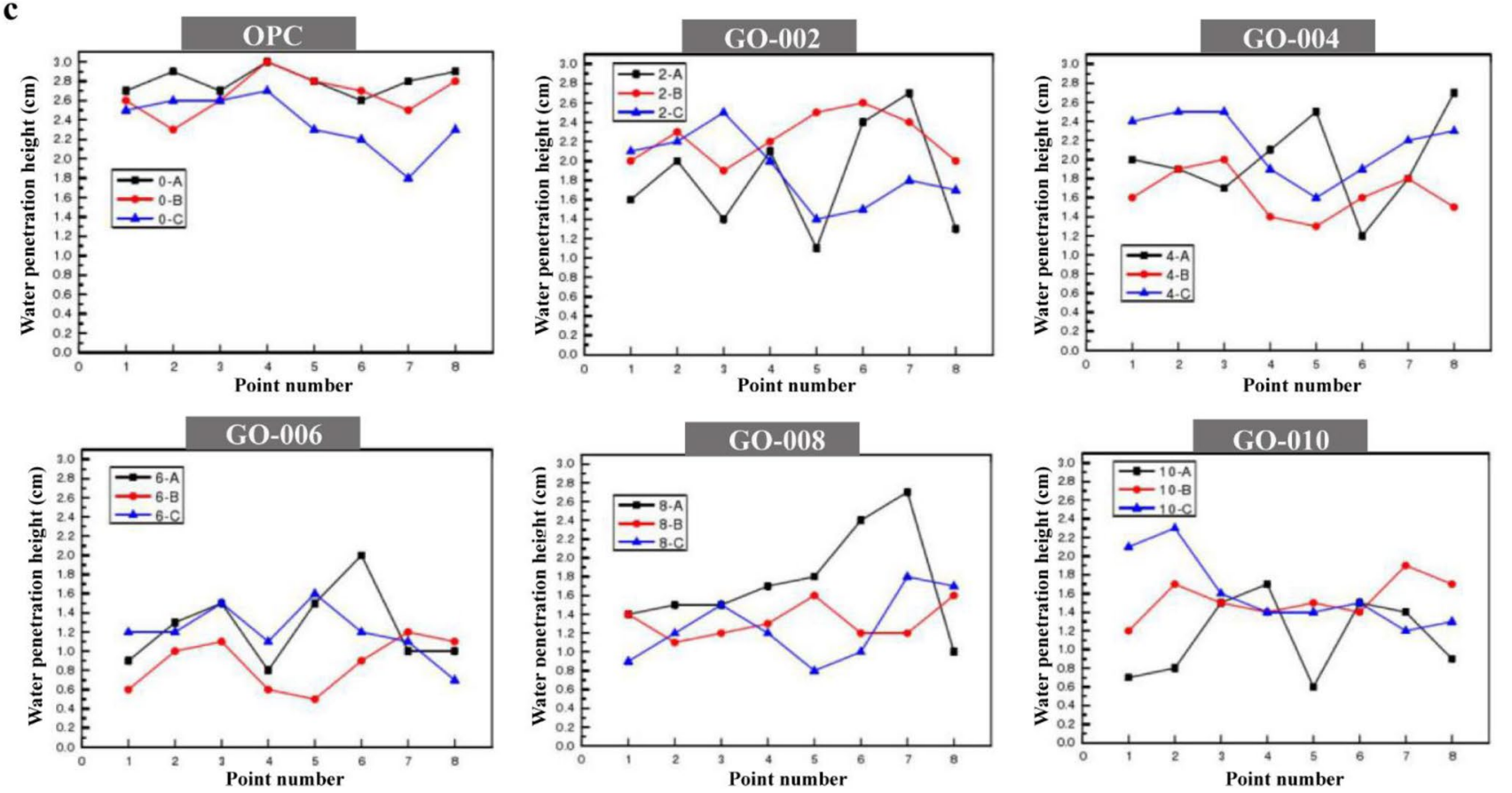

d
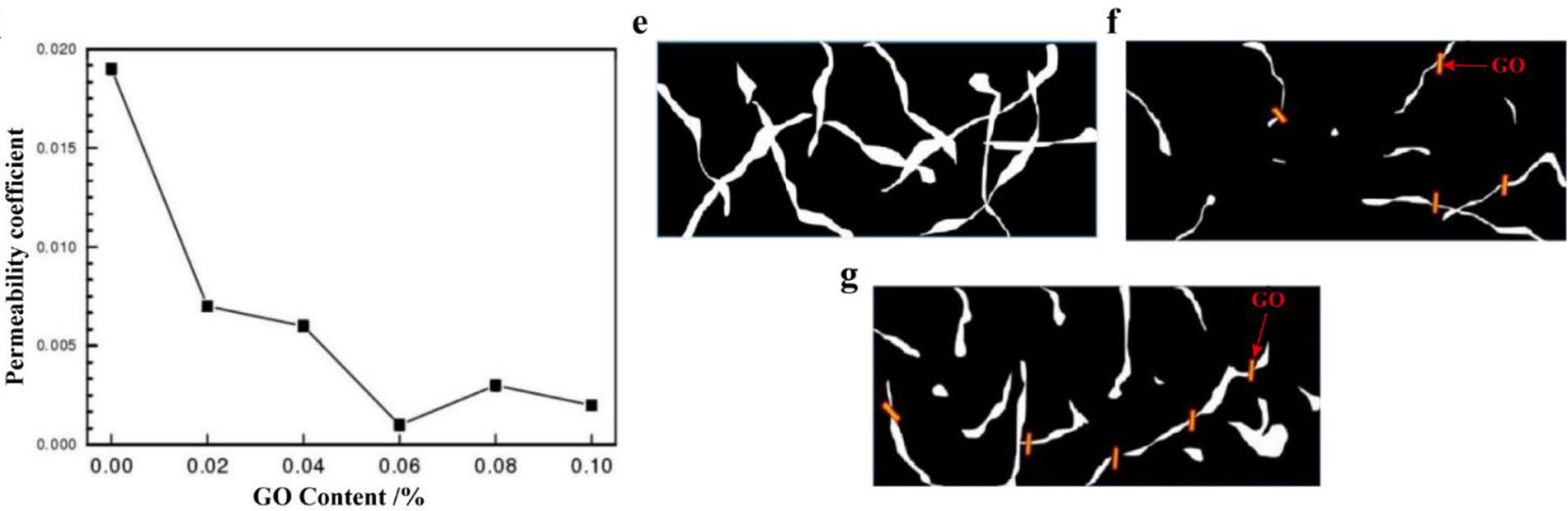

Fig. 7 a Effects of GO content on impermeability; $\mathbf{b}$ impermeability of split specimen surfaces; c measured impermeability value; $\mathbf{d}$ GO/ CNTs effects on permeability coefficient; e large porosity and high permeability; f low porosity and low permeability; $\mathbf{g}$ large porosity and low permeability 
Table 8 Relevant parameters of permeability coefficient

\begin{tabular}{llllll}
\hline Specimen number & $\begin{array}{l}\text { Average penetration } \\
\text { depth }(\mathrm{cm})\end{array}$ & $\begin{array}{l}\text { Pressure test } \\
\text { time }(\mathrm{h})\end{array}$ & $\Delta \mathrm{P}(\mathrm{MPa})$ & $\Delta \mathrm{m}(\mathrm{g})$ & $\mathrm{Ah}\left(\mathrm{cm}^{3}\right)$ \\
\hline OPC & 2.61 & 4 & 0.4 & 1.2 & 132.73 \\
GO-002 & 1.99 & 4 & 0.4 & 0.8 & 132.73 \\
GO-004 & 1.93 & 4 & 0.4 & 0.7 & 132.73 \\
GO-006 & 1.10 & 4 & 0.4 & 0.4 & 132.73 \\
GO-008 & 1.45 & 4 & 0.4 & 0.6 & 132.73 \\
GO-010 & 1.43 & 4 & 0.4 & 0.5 & 132.73 \\
\hline
\end{tabular}

Acknowledgements The authors would like to thank all the staff and technicians in the Laboratory of Hunan University (China) for their kind assistance with laboratory testing including data analysis and documentation of this work. The contents of this paper (which is not a standard nor specification) reflect the views of the authors who are solely responsible for the facts and accuracy of the data presented herein and do not necessarily reflect the official views or policies of any agency or institute. Trade names were used solely for information purposes and not for product endorsement, advertisement, promotions, or certification.

\section{Compliance with ethical standards}

Conflict of interest The authors declare that they have no conflict of interest.

\section{References}

1. Zhao L, Guo X, Liu Y, Zhao Y, Chen Z, Zhang Y, Guo L, Shu X, Liu $J$ (2018) Hydration kinetics, pore structure, 3D network calcium silicate hydrate, and mechanical behavior of graphene oxide reinforced cement composites. Constr Build Mater 190:150-163. https://doi.org/10.1016/j.conbuildmat.2018.09.105

2. Zhao H, Qin X, Liu J, Zhou L, Tian Q, Wang P (2018) Pore structure characterization of early-age cement pastes blended with high-volume fly ash. Constr Build Mater 189:934-946. https:// doi.org/10.1016/j.conbuildmat.2018.09.023

3. Zhang G, Li G, Li Y (2016) Effects of superplasticizers and retarders on the fluidity and strength of sulphoaluminate cement. Constr Build Mater 126:44-54. https://doi.org/10.1016/j.conbu ildmat.2016.09.019

4. Pradhan S, Kumar S, Barai SV (2017) Recycled aggregate concrete: particle packing method (PPM) of mix design approach. Constr Build Mater 152:269-284. https://doi.org/10.1016/j. conbuildmat.2017.06.171

5. Sassani A, Ceylan H, Kim S, Gopalakrishnan K, Arabzadeh A, Taylor PC (2017) Influence of mix design variables on engineering properties of carbon fiber-modified electrically conductive concrete. Constr Build Mater 152:168-181. https://doi.org/10.1016/j. conbuildmat.2017.06.172

6. Yıldırım G, Dündar B, Alam B, Şahmaran M (2018) Role of nanosilica on the early-age performance of natural pozzolan-based blended cement. ACI Mater J. https://doi.org/10.14359/51706 848

7. Al-Najjar Y, Yeşilmen S, Al-Dahawi AM, Şahmaran M, Yıldırım G, Lachemi M, Amleh L (2016) Physical and chemical actions of nano-mineral additives on properties of high-volume fly ash engineered cementitious composites. ACI Mater J. https://doi. org/10.14359/51689114
8. Zhang P, Li QF, Zhu HT, Zhang TH (2017) Fracture tough-

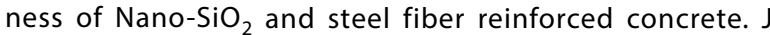
Build Mater 20(03):366-372. https://doi.org/10.3969/j. issn.1007-9629.2017.03.008

9. Mo L, Panesar DK (2012) Effects of accelerated carbonation on the microstructure of Portland cement pastes containing reactive MgO. Cem Concr Res 42(6):769-777. https://doi. org/10.1016/j.cemconres.2012.02.017

10. Yeşilmen S, Al-Najjar Y, Balav MH, Şahmaran M, Yıldırım G, Lachemi M (2015) Nano-modification to improve the ductility of cementitious composites. Cem Concr Res 76:170-179. https ://doi.org/10.1016/j.cemconres.2015.05.026

11. Li GY, Wang PM (2005) Microstructure and mechanical properties of carbon nanotubes cement matrix composites. J Chin Ceram Soc 01:105-108. https://doi.org/10.14062/j.i ssn.0454-5648.2005.01.021

12. Mohsen MO, Taha R, Abu Taqa A, Shaat A (2017) Optimum carbon nanotubes' content for improving flexural and compressive strength of cement paste. Constr Build Mater 150:395-403. https://doi.org/10.1016/j.conbuildmat.2017.06.020

13. Zhou C, Li F, Hu J, Ren M, Wei J, Yu Q (2017) Enhanced mechanical properties of cement paste by hybrid graphene oxide/carbon nanotubes. Constr Build Mater 134:336-345. https://doi. org/10.1016/j.conbuildmat.2016.12.147

14. Al-Dahawi A, Sarwary MH, Öztürk O, Yıldırım G, Akın A, Şahmaran M, Lachemi M (2016) Electrical percolation threshold of cementitious composites possessing self-sensing functionality incorporating different carbon-based materials. Smart Mater Struct. https://doi.org/10.1088/0964-1726/25/10/105005

15. Prabavathy S, Jeyasubramanian K, Prasanth S, Hikku GS, Robert RBJ (2020) Enhancement in behavioral properties of cement mortar cubes admixed with reduced graphene oxide. J Build Eng. https://doi.org/10.1016/j.jobe.2019.101082

16. Lv S, Liu J, Sun T, Ma Y, Zhou Q (2014) Effect of GO nanosheets on shapes of cement hydration crystals and their formation process. Constr Build Mater 64:231-239. https://doi.org/10.1016/j. conbuildmat.2014.04.061

17. Öztürk O, Yıldırım G, Keskin ÜS, Siad H, Şahmaran M (2020) Nano-tailored multi-functional cementitious composites. Compos B Eng. https://doi.org/10.1016/j.compositesb.2019.107670

18. Yıldırım G, Öztürk O, Al-Dahawi A, Ulu AA, Şahmaran M (2020) Self-sensing capability of engineered cementitious composites: effects of aging and loading conditions. Constr Build Mater. https://doi.org/10.1016/j.conbuildmat.2019.117132

19. Sarwary MH, Yıldırım G, Al-Dahawi A, Anıl Ö, Khiavi KA, Toklu K, Şahmaran M (2019) Self-sensing of flexural damage in largescale steel-reinforced mortar beams. ACI Mater J. https://doi. org/10.14359/51715581

20. Yıldırım G, Sarwary MH, Al-Dahawi A, Öztürk O, Anıl Ö, Şahmaran M (2018) Piezoresistive behavior of CF-and CNT-based reinforced concrete beams subjected to static flexural loading: shear failure investigation. Constr Build 
Mater 168:266-279. https://doi.org/10.1016/j.conbuildma t.2018.02.124

21. Tong T, Fan Z, Liu Q, Wang S, Tan S, Yu Q (2016) Investigation of the effects of graphene and graphene oxide nanoplatelets on the micro- and macro-properties of cementitious materials. Constr Build Mater 106:102-114. https://doi.org/10.1016/j. conbuildmat.2015.12.092

22. Kim GM, Nam IW, Yang B, Yoon HN, Lee HK, Park S (2019) Carbon nanotube (CNT) incorporated cementitious composites for functional construction materials: the state of the art. Compos Struct. https://doi.org/10.1016/j.compstruct.2019.111244

23. Li D, Muller MB, Gilje S, Kaner RB, Wallace GG (2008) Processable aqueous dispersions of graphene nanosheets. Nat Nanotechnol 3(2):101-105. https://doi.org/10.1038/nnano.2007.451

24. Ministry of Housing and Urban-Rural Development of the People's Republic of China (MOHURD) (2011) JGJ 55-2011 Specification for mix proportion design of ordinary concrete. China Architecture \& Building Press, Beijing

25. Liu Q, Xu Q, Yu Q, Gao R, Tong T (2016) Experimental investigation on mechanical and piezoresistive properties of cementitious materials containing graphene and graphene oxide nanoplatelets. Constr Build Mater 127:565-576. https://doi. org/10.1016/j.conbuildmat.2016.10.024

26. Ministry of Housing and Urban-Rural Development of the People's Republic of China (MOHURD) (2019) GB/T 50081-2019 Standard for test method of concrete physical and mechanical properties. China Architecture \& Building Press, Beijing

27. Ministry of Housing and Urban-Rural Development of the People's Republic of China (MOHURD) (2009) JGJ/T 70-2009 Standard for test method of basic properties of construction mortar. China Architecture \& Building Press, Beijing

28. Ministry of Housing and Urban-Rural Development of the People's Republic of China (MOHURD) (2009) GB/T 50082-2009 Standard for test methods of long-term performance and durability of ordinary concrete. China Architecture \& Building Press, Beijing

29. Shang Y, Zhang D, Yang C, Liu Y, Liu Y (2015) Effect of graphene oxide on the rheological properties of cement pastes. Constr Build Mater 96:20-28. https://doi.org/10.1016/j.conbuildma t.2015.07.181

30. Wang M, Wang R, Yao H, Wang Z, Zheng S (2016) Adsorption characteristics of graphene oxide nanosheets on cement. RSC Adv 6(68):63365-63372. https://doi.org/10.1039/c6ra10902k

31. Wang Q, Cui X, Wang J, Li S, Lv C, Dong Y (2017) Effect of fly ash on rheological properties of graphene oxide cement paste. Constr Build Mater 138:35-44. https://doi.org/10.1016/j.conbu ildmat.2017.01.126

32. Pan Z, He L, Qiu L, Korayem AH, Li G, Zhu JW, Collins F, Li D, Duan WH, Wang MC (2015) Mechanical properties and microstructure of a graphene oxide-cement composite. Cem Concr Compos 58:140-147. https://doi.org/10.1016/j.cemconcomp .2015.02.001

33. Li W, Li X, Chen SJ, Liu YM, Duan WH, Shah SP (2017) Effects of graphene oxide on early-age hydration and electrical resistivity of Portland cement paste. Constr Build Mater 136:506-514. https://doi.org/10.1016/j.conbuildmat.2017.01.066

34. Xu S, Liu J, Li Q (2015) Mechanical properties and microstructure of multi-walled carbon nanotube-reinforced cement paste. Constr Build Mater 76:16-23. https://doi.org/10.1016/j.conbuildma t.2014.11.049

35. Cui X, Han B, Zheng Q, Yu X, Dong S, Zhang L, Ou J (2017) Mechanical properties and reinforcing mechanisms of cementitious composites with different types of multiwalled carbon nanotubes. Compos A Appl Sci Manuf 103:131-147. https://doi. org/10.1016/j.compositesa.2017.10.001

36. Siddique R, Mehta A (2014) Effect of carbon nanotubes on properties of cement mortars. Constr Build Mater 50:116-129. https ://doi.org/10.1016/j.conbuildmat.2013.09.019

37. Cai Y, Hou P, Duan C, Zhang R, Zhou Z, Cheng X, Shah S (2016) The use of tetraethyl orthosilicate silane (TEOS) for surface-treatment of hardened cement-based materials: a comparison study with normal treatment agents. Constr Build Mater 117:144-151. https://doi.org/10.1016/j.conbuildmat.2016.05.028

38. Björnström J, Martinelli A, Matic A, Börjesson L, Panas I (2004) Accelerating effects of colloidal nano-silica for beneficial calcium-silicate-hydrate formation in cement. Chem Phys Lett 392(1-3):242-248. https://doi.org/10.1016/j.cplett.2004.05.071

39. YImén R, Jäglid U, Steenari B-M, Panas I (2009) Early hydration and setting of Portland cement monitored by IR, SEM and Vicat techniques. Cem Concr Res 39(5):433-439. https://doi. org/10.1016/j.cemconres.2009.01.017

40. Choudhary HK, Anupama AV, Kumar R, Panzi ME, Matteppanavar S, Sherikar BN, Sahoo B (2015) Observation of phase transformations in cement during hydration. Constr Build Mater 101:122129. https://doi.org/10.1016/j.conbuildmat.2015.10.027

41. Bw Jo, Chakraborty S, Sikandar MA, Kim H, Kim KH (2015) Hydrogen-rich water revealed benefits in controlling the physical and mechanical performances of cement mortar. Constr Build Mater 100:31-39. https://doi.org/10.1016/j.conbuildmat.2015.09.014

42. Pan X, Shi Z, Shi C, Hu X, Wu L (2016) Interactions between inorganic surface treatment agents and matrix of Portland cementbased materials. Constr Build Mater 113:721-731. https://doi. org/10.1016/j.conbuildmat.2016.03.091

43. Sun G, Liang R, Lu Z, Zhang J, Li Z (2016) Mechanism of cement/ carbon nanotube composites with enhanced mechanical properties achieved by interfacial strengthening. Constr Build Mater 115:87-92. https://doi.org/10.1016/j.conbuildmat.2016.04.034

44. Izadifar M, Königer F, Gerdes A, Wöll C, Thissen P (2019) Correlation between composition and mechanical properties of calcium silicate hydrates identified by infrared spectroscopy and density functional theory. J Phys Chem C 123(17):10868-10873. https://doi.org/10.1021/acs.jpcc.8b11920

45. Wang M, Wang R, Yao H, Farhan S, Zheng S, Du C (2016) Study on the three-dimensional mechanism of graphene oxide nanosheets modified cement. Constr Build Mater 126:730-739. https://doi.org/10.1016/j.conbuildmat.2016.09.092

46. Yu Z, Ni C, Tang M, Shen X (2018) Relationship between water permeability and pore structure of Portland cement paste blended with fly ash. Constr Build Mater 175:458-466. https:// doi.org/10.1016/j.conbuildmat.2018.04.147

47. Martin WD, Kaye NB, Putman BJ (2014) Impact of vertical porosity distribution on the permeability of pervious concrete. Constr Build Mater 59:78-84. https://doi.org/10.1016/j.conbuildma t.2014.02.034

48. Walubita LF, Das G, Espinoza E, Oh J, Scullion T, Lee SI, Garibay GL, Nazarian S, Abdallah I (2012) Texas flexible pavements and overlays: year 1 report, test sections, data collection, analyses, and data storage system (No. FHWA/TX-12/0-6658-1). Texas Transportation Institute (TTI), College Station

49. Zhao TJ (2006) Concrete permeability. Science Press, Beijing, pp 23-24

Publisher's Note Springer Nature remains neutral with regard to jurisdictional claims in published maps and institutional affiliations. 